\title{
"A cruz de Cristo" nas fábricas e nas escolas: Amélia de Rezende Martins e a Ação Social Brasileira (ASB)
}

\author{
"The cross of Christ" in factories and schools: \\ Amélia de Rezende Martins and \\ the Ação Social Brasileira (ASB)
}

AMANDA HAYDN ${ }^{\mathrm{a}}$

Mauro CAstilho GonçALVES ${ }^{b}$

\section{Resumo}

O presente artigo examina aspectos relacionados à trajetória política e intelectual de Amélia de Rezende Martins (1877-1948), nos âmbitos da educação e da cultura, privilegiadamente entre os anos de 1918 a 1932. A justificativa da periodização proposta ateve-se ao fato de que foi nessa fase que Martins publicou suas ideias, veiculou seus projetos e atuou em organismos ligados à educação escolar e à cultura em geral. Destacam-se, nesses âmbitos, a imprensa periódica carioca, a Associação Brasileira de Educação (ABE) e a Ação Social Brasileira (ASB). Na pesquisa foram utilizadas fontes disponíveis nos Arquivos da Fundação Casa de Rui Barbosa (FCRB), da Associação Brasileira de Educação ( $A B E$ ) e do Centro de Memória da Universidade de Campinas (Unicamp). Na imprensa, foi objeto de análise a atuação de Martins nos jornais $A$ União, O Paiz, A Cruz, Correio da Manhã, Jornal do Brasil, O Jornal e A Noite e Diário de Notícias. $A$ análise indicou que Martins foi uma intelectual preocupada com a construção de um projeto cultural para o Brasil. Tal projeto, denominado Ação Social Brasileira (ASB), constituiu-se em essência em um anteprojeto para a fundação de uma instituição educacional e de assistência social - o Edifício Anchieta - uma forte aposta de Martins na educação como força capaz de resolver os problemas do país através da integração da classe trabalhadora em um programa de adestramento profissional, de educação moral, religiosa, cívica e higiene coletiva.

Palavras-chave: Amélia de Rezende Martins. Trajetória intelectual e política. Ação Social Brasileira.

\footnotetext{
a Pontifícia Universidade Católica de São Paulo (PUC-SP), São Paulo, SP, Brasil. Mestre em Educação, e-mail: amandahaydn@gmail.com

b Pontifícia Universidade Católica de São Paulo (PUC-SP), São Paulo, SP, Brasil. Doutor em Educação, e-mail:mauro_castilho@uol.com.br
} 


\begin{abstract}
The present paper examines aspects related to the political and intellectual trajectory of Amélia de Rezende Martins (1877-1948), in the spheres of education and culture, between 1918 and 1932. The justification for the proposed periodization adhered to the fact that at this period Martins published her ideas, implemented her projects and acted in organizations related to school education and overall culture. The periodic press in Rio de Janeiro, the Associação Brasileira de Educação (ABE) and the Ação Social Brasileira (ASB) stand out in these areas. In the research, sources available in the archives of the Fundação Casa de Rui Barbosa, the Associação Brasileira de Educação (ABE) and the Memory Center of University of Campinas (UNICAMP) were used. In the press, metions of Rezende Martins in the newspapers A União, O Paiz, A Cruz, Correio da Manhã, Jornal do Brasil, O Jornal, A Noite e Diário de Notícias were analyzed, these sources are considered central in the scope of the presente study. The analysis of the selected sources indicated that Martins was an intellectual concerned with the construction of a cultural project for Brazil. This project, called Ação Social Brasileira (ASB), was essentially a preliminary project for the foundation of an educational institution and social assistance, the Anchieta Building, Martins' strong bet on education as a force capable of solving country's problems through the integration of the working class into a program of professional training, moral education, religious education, civic education and collective hygiene.
\end{abstract}

Keywords: Amélia de Rezende Martins. Intellectual and political trajectory. Ação Social Brasileira.

\title{
Introdução
}

Este artigo tem por objetivo analisar o itinerário da escritora, conferencista e publicista Amélia de Rezende Martins (1877-1948) entre os anos de 1918 a 1932. O recorte temporal escolhido é marcado por um intenso debate em torno dos rumos da educação brasileira. Debate esse sintonizado a temas como política, religião e economia que mobilizaram de maneira geral intelectuais de diversas matizes, entre eles, católicos e liberais vinculados a centros culturais e instituições para trabalharem em prol de um denominador comum: a reforma educacional, por meio da introdução das ciências e das técnicas modernas e o desenvolvimento da prática cidadã, de modo a redimensionar o sistema educacional para engendrar uma nova civilização (CARVALHO, 1998).

Entre esses intelectuais em voga no período, destaca-se a atuação de Amélia Rezende Martins, intelectual com atuação no laicato católico pré-1922 na cidade de Campinas como presidente da Associação das Mães Cristãs (1905) e, posteriormente, na 
cidade do Rio de Janeiro como idealizadora do projeto Ação Social Brasileira (1918-1932).

Das fontes privilegiadas pela pesquisa destacamos: revistas, missivas, folhetos, livros memorialísticos e jornais de circulação no período, disponíveis nos arquivos das instituições Fundação Casa de Rui Barbosa (FCRB), Associação Brasileira de Educação (ABE) e Centro de Memória da Universidade de Campinas (Unicamp). Na imprensa, foi objeto de análise a atuação de Rezende Martins nos jornais $A$ União, $O$ Paiz, A Cruz, Correio da Manhã, Jornal do Brasil, O Jornal, A Noite e Diário de Notícias. Ligada a grupos católicos, Martins circulou em diferentes instituições e a investigação se propôs a mapear sua atuação, a partir de referenciais teórico-analíticos sugeridos por Sirinelli (2003), tais como: geração, itinerário, redes de sociabilidade e produção intelectual. Esses permitiram investigar em perspectiva histórica a sua formação e seus coletivos, seus espaços e redes de relacionamentos sociais, intelectuais e políticos, bem com verificar o alcance de sua intervenção como intelectual.

Entendeu-se que, para estudar e decifrar o fazer histórico de Amélia de Rezende Martins no ato de sua produção intelectual e de sua atuação política foi necessário considerar duas questões fundamentais: primeiramente, entender que a história como disciplina tem um método lógico de investigação adequado a materiais históricos, destinado, na medida do possível, a testar hipóteses quanto às noções de estrutura, causação, de contradição, de mediação e de organização de vida social, política, econômica e intelectual (THOMPSON, 1981), em segundo, foi preciso pensar nas possibilidades de Amélia de Rezende, mesmo que sob certas circunstâncias, enquanto sujeito ativo na construção de sua história. Distanciando-se, portanto, de um entendimento histórico que anula o sujeito.

É importante ainda dizer que ao investigar o fazer histórico de Martins, com recortes que a valorizam como sujeito ou como indivíduo histórico, não levou à abstenção de um tipo de conhecimento mais estrutural. Ou seja, a trajetória de Amélia de Rezende, nesse caso, constituiu-se também como uma entrada para a compreensão de projetos, atores, políticas e contextos sociais mais amplos do que aqueles circunscritos à sua vida pessoal.

O presente artigo, a partir das considerações apresentadas, está dividido em duas partes. Na primeira, a discussão privilegia a trajetória de Martins desde seus 
primeiros anos de formação na cidade de Campinas até sua saída para cidade do Rio de Janeiro, com ênfase não somente em sua formação intelectual, mas nos ambientes de sua socialização, com atenção às redes de relações que estabeleceu e heranças culturais e políticas das quais se apropriou. $\mathrm{Na}$ segunda parte, objetiva-se compreender sua proposta educacional e seu projeto de organização social a Ação Social Brasileira.

\section{Na moldura da memória: Amélia de Rezende Martins (1877-1948)}

Amélia de Rezende Martins nasceu em 23 de março de 1877 na cidade de Campinas/SP. Uma década marcada pelo surgimento de uma série de sintomas de crise do Segundo Reinado: o início do movimento republicano, o problema da escravidão e os atritos do governo imperial com o exército e a Igreja (FAUSTO, 2013). Mas também um período em que se anunciavam "novos tempos" marcado pela modernização na infraestrutura econômica - devido a prosperidade advinda da comercialização do café que estimulou a industrialização e a urbanização, pela chegada do trem de ferro, do bonde elétrico, da iluminação a gás e do trabalho assalariado de milhares de imigrantes (LAPA, 1996).

Em linhas gerais, Campinas acompanhou as grandes mudanças econômicas, sociais e políticas que ocorreram em nível nacional na segunda metade do século XIX. Contudo, apesar de existir consenso na literatura sobre o avanço da modernidade no Brasil nesse período, é necessário ter cautela na avaliação do fenômeno (CARVALHO, 1998).

É preciso matizar as propostas e os alcances desses projetos modernizadores para a população, pois, como descreveu Carvalho (1998), embora, a partir de 1870, tenha se avançado em alguns aspectos, na modernização do Brasil predominou a tradição, o mundo agrário, aristocrático, pré-industrial e pré-burguês (CARVALHO, 1998, p. 125).

E entre aqueles que se beneficiaram diretamente com esse desenvolvimento acentuado do café, que se atualizaram com o progresso advindo da modernização, e, que em troca, "mantiveram a estrutura subdesenvolvida de amplos contingentes da 
população" (LAPA, 1996, p. 20), estava a camada social cuja família de Amélia é a típica representante, ou seja, aquela que detinha os meios de produção e, em consequência, o poder econômico e político: a aristocracia cafeeira.

Amélia de Rezende Martins era neta por parte paterna do Marquês de Valença (Estevão Ribeiro de Rezende) e da Marquesa de Valença (Ilídia Mafalda de Souza Queiroz). Seu pai, Geraldo Ribeiro de Souza Rezende, o barão Geraldo de Rezende, nasceu no Rio de Janeiro em 19 de abril de 1847. Casou-se em 20 de junho de 1876, na Igreja "Santo Antonio dos Pobres" (MARTINS, 1939, p. 161) com sua prima, Maria Amélia Barbosa de Oliveira (Baronesa Geraldo de Rezende), primeira filha do conselheiro imperial, Albino José Barbosa de Oliveira e de Izabel Augusta de Souza Queiroz (sobrinha de Ilídia Mafalda de Souza Queiroz e neta do Brigadeiro Luiz Antônio de Souza Queiroz), “o maior proprietário de terras na província de São Paulo" (PERECIN, 2004, p. 109). A herança do brigadeiro, partilhada em 1819, rendeu bens avultados aos seus descendentes, conforme descreveu a sua bisneta, Amélia de Rezende:

\begin{abstract}
Era de opulencia o ambiente em que viveu meu pae. Grandes propriedades possuira o Marquez de Valença no Rio de Janeiro antigo, passando em herança para minha avó e para os filhos. [...] constam em nome de minha avó, onze sobrados na rua do Senado, do numero 59 ao 79, cinco prédios na rua dos Invalidos [...] Além desses próprios da cidade, minha avó possuía uma casa de residencia em Valença,- onde foi hospedado o Imperador, por ocasião de sua visita a essa localidade-, e muitas terras [...] E só conheço da grande fortuna de meu avô e de minha avó, que herdára avultados bens de seu pae, o Brigadeiro Luiz Antonio, a maior fortuna da Capitania de São Paulo e uma das maiores do Brasil (MARTINS, 1939, p. 59-60).
\end{abstract}

Assim sendo, os pais da futura militante católica pertenciam as antigas famílias da aristocracia rural que se formaram no Brasil e que pela posição social e educação pode ser equiparada à classe privilegiada europeia do mesmo período. Nos dizeres de Rezende Martins (1939, p. 7), “em Santa Genebra, tínhamos mais progresso e mais conforto que na propria França em province”.

Em relação aos primeiros passos de sua formação, Amélia de Rezende Martins conta que foi a sua mãe, "ao lado sempre de uma professora estrangeira" (MARTINS, 1939, p. 399), quem a ensinou as primeiras letras, a tarefa doméstica, a música e a religião. Destaca que sua mãe "muito versada em literatura, poesia e música" foi 
educada no Collegio Leuzinger ${ }^{1}$, e ali começou, além do programa do curso colegial, um estudo de piano com uma professora alemã chamada "Mlle Roller, e da lingua allemã com Mlle Sophie Adèle Charlotte von Lippe”. Para Martins, a "culta inteligência de sua mãe, que se irradiava pela casa" foi de fundamental importância para sua formação (MARTINS, 1939, p. 205).

Quanto ao seu pai, o barão Geraldo de Rezende, Amélia escreve que ele sempre a acompanhava em suas tarefas educativas, auxiliando-a nas leituras, no estudo do francês e do inglês, principalmente através de cartas. ${ }^{2}$ Apenas aos 9 anos, Amélia de Rezende Martins ingressa em uma escola. A opção em estudar no Colégio Progresso no Rio de Janeiro partiu de sua mãe, e durou apenas o período em que seu pai exerceu o cargo de deputado geral pelo $7^{\circ}$ Distrito de São Paulo (1886-1889) ${ }^{3}$.

Outro ponto a destacar é que a nossa personagem nasceu e cresceu em ambiente de forte arreigo monarquista. Seu pai, Geraldo Ribeiro de Souza Rezende, além de proprietário da fazenda Santa Genebra foi presidente do diretório do partido conservador em 1884, posto que conservou até o fim da monarquia. Foi considerado ainda um dos artífices e cooperadores do Club da Lavoura de Campinas, movimento da política de valorização do café paulistano ao lado de seu fundador e amigo Joaquim Bonifácio do Amaral, o Visconde de Indaiatuba.

"Monarchista de integridade absoluta" (MARTINS, 1939, p. 284) recebeu o título de barão de Iporanga antes da Proclamação da República por decreto de 19 de junho de 1889, assinado pela sua majestade imperial D. Pedro II, tendo mudado, a seu pedido, para barão Geraldo de Rezende. A questão chave aqui é que, a família de Rezende Martins também possuía laços estreitos de amizade com o imperador. Seu tio Estevão de Ribeiro de Rezende ou barão de Rezende, por exemplo, era afilhado de batismo de D. Pedro II e de "Sua Augusta Irmã a Princeza Senhora Dona Francisca, Princesa de Joinville” (MARTINS, 1939, p. 69). Amélia de Rezende nos conta que na passagem do imperador em Piracicaba, em 1886, foi seu tio, o barão de

\footnotetext{
1 Segundo Borges (2004, p.9) o "Colégio de Madame Leuzinger" situado na "Rua do Príncipe do catete, 25 " era uma escola de 60 alunas, somente para instrução primária.

${ }^{2}$ Sobre a dimensão educativa das cartas na interiorização dos valores burgueses ver: Malatian (2009).

${ }^{3}$ Era a província de São Paulo dividida em nove distritos oferecendo, portanto, à Câmara, nove deputados gerais. Com a vaga do conselheiro Martim Francisco, nova eleição foi marcada, no seu lugar assume o pai de Amélia de Rezende em 11 de agosto de 1886 (MARTINS, 1939, p. 356).
} 
Rezende, quem hospedou D. Pedro II, a imperatriz Thereza Christina e toda a comitiva em sua residência.

Assim, tudo indica que esse meio onde Martins se criou, tradicionalmente animado e condicionado pela "extremada convicção monarchica" de seus familiares (MARTINS, 1939, p. 167), foi o que marcou, de certa forma, parte de suas aspirações, atitudes e atividades no período de sua vida adulta. Além disso, cumpre destacar que ao longo de sua trajetória, a religião católica influenciou decididamente a sua formação, aspecto que merece atenção.

A gênese de sua formação religiosa coincidiu com o período em que o padre João Batista Corrêa Nery ${ }^{4}$ esteve à frente da paróquia Nossa Senhora do Carmo de Santa Cruz ${ }^{5}$, entre 1887 e 1894, estendendo-se até sua atuação como primeiro bispo de Campinas entre 1908 e 1920. A ligação de Rezende Martins com esse prelado render-lhe-ia a sua aproximação ao paradigma do catolicismo social, apregoado desde a publicação da Rerum Novarum, documento pontifício escrito por Leão XIII em 1891, e a sua primeira iniciativa no apostolado leigo feminino, como vice-presidente da Associação das Mães Cristãs, entidade fundada em fevereiro de 1905, iniciativa do então ainda pároco Francisco de Campos Barreto.

Diga-se ainda, que esta identidade confirmada no catolicismo de Rezende Martins, foi "revitalizada" (BERGER; LUCKMANN, 1996) por outro acontecimento em sua trajetória, que vale a pena mencionar. Em 1894, Martins, contando apenas com 17 anos, casa-se, em 10 de novembro, com o médico João de Assis Lopes Martins. Segundo Sérgio Vale (2004), João de Assis Lopes Martins foi aquele que, ao lado de outras figuras expressivas da cidade de Campinas, como Francisco Glicério César Bierrenbach, Orozimbo Maia, Júlio Frank de Arruda, Antônio Carlos do Amaral Lapa, Roque de Marco, Antônio Benedito de Castro Mendes, sob liderança de Dom Nery e do padre Francisco de Campos Barreto, movimentou-se no sentido de tornar realidade a proposta de criação da Diocese de Campinas, a qual a Santa Sé não considerou oportuna, entre outras razões, por ser Campinas cidade muito próxima de São Paulo.

\footnotetext{
${ }^{4}$ Sobre Dom João Batista Correa Nery (1863-1920) ver: VALE et al. (2004) e RIGOLO FILHO (2006).

${ }^{5}$ Atual Paróquia Nossa Senhora do Carmo. Ver: VALE et al. (2004).
} 
João de Assis também foi presidente da Liga da Boa Imprensa (LBI) em Campinas, sua inserção na diretoria da Liga em 1905 possibilitou estreitar os laços de sociabilidade entre o assistente eclesiástico da LBI, Francisco de Campos Barreto, e Amélia de Rezende, que agora, com aos 28 anos, sentia a necessidade de atuar mais decisivamente em favor da instituição. Assim, em 2 de fevereiro de 1905, o padre Barreto funda a Associação das Mães Cristãs tendo na sua diretoria, como vicepresidente, Amélia de Rezende Martins. De acordo com José Pedro Soares Martins (2010), a Associação das Mães Cristãs tinha por objetivo a promoção de reuniões, a participação em missas e orações como meio para conseguir a disseminação da fé no meio das famílias. A associação era vinculada à Arquiconfraria de Paris, sob o título de Nossa Senhora do Carmo, e teve como principal padroeira Santa Mônica.

Louis-Marie de Bazelaire, arcebispo de Chambéry, em sua obra, Os leigos também são a igreja de 1960, afirmou que, no curso da histórica católica, a Igreja pôs em evidencia alguns "tipos femininos" como forma de demonstrar que as mulheres cooperam tão eficazmente quanto os homens em sua expansão. Eis a "virgem cristã", a "esposa cristã" como Santa Clotilde que trouxe a fé cristã ao seu marido Clóvis, por exemplo.

Para o autor o apostolado feminino terá sempre como referência algum "tipo feminino" que servirá de modelo para atuação das mulheres da instituição. No caso da Associação das Mães Cristãs, o tipo que prevalece é o da "mãe cristã”, aquela cuja oração e lágrimas garantem a fidelidade para seus filhos ou a sua conversão. Uma referência à Santa Mônica que não desanimava em suas preces implorando a Deus a conversão do futuro Santo Agostinho.

Foi nessa perspectiva de "mãe cristã" que Amélia de Rezende Martins deu seus primeiros passos no movimento de reforma católica na cidade campineira. Seu papel fora o apostolado através do ensino dos valores católicos em todo ambiente que viesse ocupar. Sua missão não era diferente das de seus grandes mestres da catequização: converter e educar almas ao catolicismo, educar futuros militantes e aspirantes intelectuais católicos para suas ações na sociedade brasileira em áreas de interesse da Igreja para defender e representá-la, como uma boa “mãe cristã" que converte os filhos. 
Amélia entregou-se à fé, não apenas parcialmente, mas com o que é subjetivamente a totalidade da sua vida. Pode-se dizer que a sua socialização nesse contexto citadino, cultural e religioso adquiriu uma carga de afetividade de tal grau que a imersão na nova realidade e o devotamento a ela foram institucionalmente necessários ao ponto de, conforme afirma Aline Coutrot (2003), subtender suas atitudes sociais e políticas.

E ao mudar-se para o estado do Rio de Janeiro, Amélia de Rezende consolidou essas experiências, conhecimentos e cumplicidade com outros leigos e eclesiásticos. Foi na antiga capital do país que a escritora desenvolveu com maior consistência o sentido do movimento católico. A questão da emergência de novas classes sociais, especialmente o operariado, e a resolução dos problemas sociais brasileiros, nomeadamente por meio da veiculação de uma cultura política associada à pregação da dimensão social da Igreja Católica, presente na Encíclica Rerum Novarum (1891), constituíram-se em uma linha de frente de sua atuação. Conforme bem definiu Soares D’ Azevedo (1920, p. 1) em um trecho publicado no jornal A União:

\footnotetext{
Neste velho Brasil só faz alguma coisa, em assumpto de acção social catholica, quem tem uma vontade de aço para querer [...] Amelia de Rezende Martins. Podia-se, e sê-lo perfeitamente, a cabeça de um movimento feminino que arrastasse atraz de si todos os valores enfeixados em mãos de mulheres catholicas brasileiras.
}

É sobre essa marca característica da trajetória de Martins, como intelectual engajada no militante movimento católico, que se organizou na cidade do Rio de Janeiro, sob os auspícios de Dom Sebastião Leme da Silveira Cintra (1882-1942) ${ }^{6}$, que trataremos a seguir.

\section{Entre intelectuais católicos na cidade do Rio de Janeiro: A rede de sociabilidade de Amélia de Rezende Martins}

Não é possível afirmar a data correta da migração de Amélia de Rezende e sua família para o estado do Rio de Janeiro. A pesquisa se atém na hipótese de que Amélia

\footnotetext{
${ }^{6}$ Sobre Dom Sebastião Leme da Silveira Cintra ver: Oliveira (2016). 
de Rezende e sua família instalaram-se de forma permanente no bairro das Laranjeiras, na cidade do Rio de Janeiro, em meados de 1920. Cabe destacar que este foi um período em que Martins manteve e intensificou suas relações pessoais de amizade com diferentes prelados e figuras católicas de grande significação, clérigos e leigos.

Nessa constelação de relações, Amélia ampliou e fortaleceu suas convicções, ideias e projetos, assim como afirmou sua posição fiel aos ensinamentos pontifícios, à defesa dos interesses da Igreja e a realização de um projeto de renovação social. Esse círculo de amizade contará com a presença marcante de grandes incentivadores do apostolado social de Martins, entre eles: Jonathas Serrano, Laura Lacombe, Fernando Magalhães, Levi Carneiro, Alceu Amoroso Lima, Afonso Celso, José Piragibe, Raul Leitão Cunha, o inspetor salesiano Padre Pedro Rotta, o frei franciscano Pedro Sinzig, padre João Baptista Siqueira, D. Duarte Leopoldo e Silva, arcebispo de São Paulo, e D. Helvécio G. de Oliveira, arcebispo de Mariana (MG).

Dois clérigos merecem uma especial atenção nessa rede, são D. Joaquim Mamede da Silva Leite (1876-1947) - antigo bispo auxiliar de D. João Batista C. Nery na Diocese de Campinas (1916-1920) - e o próprio arcebispo e coadjutor D. Sebastião Leme da Silveira Cintra (1882-1942). Vale lembrar que as obras de D. Nery foram sempre coadjuvadas por D. Mamede, este, “entregue pela própria mãe em seu leito de morte ao então padre João B. Correa Nery ainda menino" (VALE et al., 2004, p. 590) tinha enorme carinho pelo bispo e partilhava do mesmo carisma, ou "afinidade ideológica ou cultural” (SIRINELLI, 2003, p. 248) em relação a obra salesiana. Podese dizer que tanto D. Mamede quanto Amélia de Rezende Martins tiveram na cidade campineira a mesma "socialização secundária afetiva e religiosa" (BERGER; LUCKMANN, 1996, p. 193) no seu processo de formação. Quando migrou para a cidade do Rio de Janeiro, D. Mamede circulou nos principais espaços de sociabilidade de Martins.

Foi, indubitavelmente, esse prelado que contribuiu para o fortalecimento e legitimação de suas ações junto a outro líder eclesiástico - D. Sebastião Leme da Silveira Cintra. Este, em 1920, ainda como arcebispo de Olinda e Recife (1916-1921), assim que soube que Martins estava na cidade, enviou-lhe uma carta para convidá-la a participar das reuniões e conferências "na tranquila sala do círculo católico, no salão 
da Associação dos Empregados no Commercio (AEC)"”7 (ARQUIVO, 1912, 1919, 1920). As fontes assinalaram que esse espaço constituiu-se em um lugar organizado de aprendizado e de trocas intelectuais que agrupou clérigos, políticos, jornalistas, escritores e professores e diretores de escolas, não necessariamente com vínculo direto à AEC.

Nesse espaço "geográfico" ou “ecossistema” (GOMES, 1999, p. 20), no interior do contexto citadino realizaram-se vários encontros, desde festas, cursos, apresentações e conferências, cujo cerne era a circulação de propostas e projetos com características socioculturais e políticas que visassem à proposição de uma identidade nacional católica, assim como contribuir para a formação e direcionamento de uma elite intelectual, que na condição de militantes e aspirantes católicos atuariam na sociedade.

Cabe destacar que Rezende Martins realizou várias conferências na AEC, assim como compartilhou e organizou diferentes projetos, cursos e festas. Foi, portanto, inserida nessa estrutura fervilhada por trocas ideológicas e/ou culturais que Rezende Martins recebeu apoio para desenvolver a sua proposta: a Ação Social Brasileira.

\section{Uma nova fundação educacional e de assistência social: o projeto ASB}

Estatuariamente, desde 1929, a ASB definia-se como uma instituição independente e nacional que tinha como objetivo auxiliar as obras sociais e educacionais já existentes por meio da construção de um edifício sede que seria levantado e organizado sob os "princípios directivos do cooperativismo" (MARTINS, 1933, p. 25).

A sociedade civil Ação Social Brasileira era composta por vários intelectuais católicos leigos, tais como Ana Nabuco de Abreu, Isabel Jacobina Lacombe, Levi Carneiro, Fernando Magalhães, Condessa Amalia Matarazzo, Raul Leitão Cunha, José

\footnotetext{
${ }^{7}$ A Associação dos Empregados no Comércio foi fundada em 7 de março de 1880. Sua missão era trabalhar para o amparo, recreação e defesa dos indivíduos desprovidos dos meios basilares de subsistência, assim como prestar assistência social, educacional, esportiva, recreativa a seus associados. Ver: www.aecrj.org.br.
} 
Piragibe, Alceu Amoroso Lima, Belisario Penna, Aderbal Pougy, João de Assis Lopes Martins, Maria Junqueira Schmidt, entre outros. Tendo como fundadora e presidente a própria Amélia de Rezende.

De acordo com Femenick (2010), o cooperativismo no Brasil caminhava muito lentamente no período anterior a 1930. Para o autor, foi somente após a crise econômica provocada pelo colapso da Bolsa de Nova Iorque em 1929 e o governo instalado pela revolução de 1930 que o estímulo para implantação de cooperativas se intensificaram no país.

Para Pereira (2001), em um intertítulo de sua obra, Cooperativas: Mudanças, Oportunidades e Desafios, denominado "Evolução histórico-jurídica do cooperativismo no Brasil", salienta que o fundamento filosófico do cooperativismo residiu na constatação da natureza gregária do ser humano e na noção axiomática de que a "união faz a força" (PEREIRA, 2001, p. 123). Para esse autor, esse sentimento de busca da vida comunitária tinha respaldo não somente no ordenamento jurídico positivo, mas também em princípios e fundamentos da vida cristã, em especial os conceitos de comunhão e solidariedade.

Sobre esse aspecto, não podemos esquecer que esse período coincidiu com a publicação da já referida encíclica do Quadragesimo Anno (1931), de Pio XI (1972). Num contexto social diferente, caracterizado pela crise do sistema capitalista, Pio XI (1972) defende a validade intemporal dos princípios de Leão XIII (1972, p. 13-47) elucidando e até mesmo aprofundando a doutrina social do predecessor. E entre os princípios que Pio XI (1972) considerava como fundamentais para a resolução da questão social estavam: o cooperativismo, a subsidiariedade ou função supletiva dos grupos, a harmonia e a cooperação entre as classes, a propriedade privada e o papel do Estado na sociedade "para que as leis e instituições sejam tais, que da própria organização do Estado dimane espontaneamente a prosperidade da nação e dos indivíduos” (PIO XI, 1972, p. 58), e por fim era necessária a reforma dos costumes na prática efetiva da caridade.

A par de uma "consciência religiosa, política e social do momento", como bem afirmou em seus escritos, Martins (s/d) assinala em sua obra, Acção Social Brasileira, que a opção pelo cooperativismo travava-se mais que um meio para realizar a construção da sede da ASB, correspondia a uma filosofia que modificaria a "arcaica" 
maneira de obter recursos das obras assistenciais, "maneira fatigante e que esgota sempre o mesmo grupo, e faz dispender energias que poderiam ser empregadas de modo mais proveitoso" (MARTINS, 1933, p. 25). E, portanto, imprescindível para resolução das questões sociais.

Em sua justificativa, Martins apontava os benefícios que o cooperativismo poderia ocasionar: a união orgânica do corpo social, por meio da transformação das crianças que se perdiam física e moralmente pelas ruas em bons servidores da Pátria, o "auxílio suplementar" aos membros da classe média que, naquele momento, necessitavam de uma solução para o trabalho. E para as "classes altas", o auxílio "para preparar o futuro dos filhos, livrando-os quanto possível do mal” (MARTINS, s.d., p. 41). Prevenir, enquanto é tempo, afirmava Martins, "para não precisar remediar, quando fôr tarde, é o plano da Acção Social Brasileira e para isso precisa da cooperação geral" (MARTINS, s.d., p. 42). Sendo uma obra que "requer grandes recursos, será feita como imensa cooperativa que congregará o Brasil inteiro" (MARTINS, 1933, p. 25).

Nesse sentido, era fundamental que "todas as classes" se unissem em torno do ideal para o levantamento e organização da sede da ASB, visto que um de seus objetivos era justamente beneficiar socialmente desde os "pequenos, a ricos e pobres, a poderosos e a deserdados" (MARTINS, s.d., p. 44). E na medida em que a ASB, fosse recebendo apoio e cooperação, aos poucos, as favelas desapareceriam para em seu lugar, aos poucos,

[...] se levantarem as Villas Proletarias; as crianças, que andam soltas pelas ruas, vagabundos de hoje que poderão ser criminosos amanhã, as crianças serão guiadas em Recreatorios, fora dos horários escolares, de modo a não serem o tormento da população e se formarem homens de bem e bons servidores da Patria; a Ação Social Brasileira tem em seu plano futuro, a fundação de Patronatos Agricolas, o que não poderá deixar de ser de grande interesse para o Governo, tão firme é a convicção geral de que a riqueza do Brasil reside em seu sólo [...] uma attenção toda especial será dada pela Aç̧ão Social Brasileira a todos os problemas educativos, constituindo isso a sua pedra angular. Para iniciar, porém, essa obra que tem tantas ramificações, cada uma por si de grande envergadura, a Acção Social Brasileira precisa da sua sede, onde as altas classes encontrarão tambem o que Ihes mereça interesse. [...] Na Acção Social Brasileira ninguem trabalhará de graça. Si a Acção Social Brasileira se levanta para auxiliar, não vai ninguém sugar energias. Ninguem trabalha de graça, nem o Estado, nem a Igreja, nem o particular [...] (MARTINS, s.d., p. 46-47).

Nota-se nestas prescrições delineadas que a fundamentação discursiva de Martins remete diretamente aos postulados da doutrina social da Igreja, 
principalmente em relação aos princípios de "unidade, cooperação e harmonia entre as classes". Pio XI (1972), em Quadragesimo Anno, rememora o princípio de unidade de São Tomás de Aquino, para fundamentar a perspectiva de que "a cura" para a desordem social provocada pela divisão das classes, e para o corpo social como um todo, encontra-se em um esforço combinado e harmônico, no sentido de que a atividade coletiva se "oriente sempre para o bem comum de toda a sociedade" (PIO XI , 1972, p. 79).

Nota-se também, um projeto de modernização nacional por meio de uma mobilização estratégica de recursos humanos, técnicos e econômicos. Um processo de formação disciplinar e de arregimentação de trabalhadores via crianças desvalidas com distribuição racional pelas atividades rurais e urbanas. Uma proposta de "defesa nacional", de crescimento industrial por meio da formação das "Villas Operárias" e da implantação dos "Recreatorios", de valorização e modernização agrícola com a implantação dos "Patronatos" e de reordenação política e educacional do país.

Em 19 de abril de 1933, Amélia de Rezende, publicou em A Noite, uma apresentação sucinta do plano Ação Social Brasileira. Na matéria, Martins (1933, p. 2.) deixa claro que se tratava de um anteprojeto para a construção de um monumento sede - o Edifício Anchieta, onde funcionaria alguns "departamentos específicos de alcance pedagógico, social e artístico". Esse skyscraper catholico como propôs Jonathas Serrano (1933), em outro artigo publicado em $A$ União ${ }^{9}$, que é bem uma metáfora do futurismo americanista, deveria ser erguido sob um complexo e rígido sistema de organização.

O plano ASB, por meio da construção desse "monumento vivo ao maior vulto da história nacional"'(MARTINS, 1933, p. 7), energizava ainda em seus futuros sócios a possibilidade ou aspiração de constituir-se em um empreendimento que, a partir do ano de sua fundação, dedicar-se-ia à formação de uma "elite católica" e à produção de uma versão católica tomista da história do Brasil, por meio de seus Gabinetes de Historia Universal e Natural, de Geografia, Physica e Chimica, sendo que um dos objetivos era o de enaltecer a obra jesuítica na histórica nacional e reafirmar os valores cristãos da sociedade brasileira, confiando o sucesso de suas

\footnotetext{
${ }^{8}$ Ver: Encíclicas e documentos sociais. DE SANCTIS (1972, p. 50-102).

${ }^{9}$ Ver: MARTINS (1933, p. 10). 
expectativas futuras, de seus planos para a Igreja no Brasil, na ação do apostolado social e educacional que a instituição continuaria a exercer. No trecho final apresentado por Martins (1934), em sua obra Quinzena Anchietana - A Acção Social Brasileira pela voz: Brasil a Anchieta (1534 - 1934) é possível robustecer a assertiva ostentada:

\begin{abstract}
Continuemos no Brasil dos nossos dias, os trabalhos de Anchieta no Brasil do passado... Os tempos são outros... o Ideal é sempre o mesmo! Ha anos vem a Acção Social Brasileira apresentando o seu plano, no qual todos os problemas que nos afligem estão carinhosamente estudados... Funccionará a Acção Social Brasileira no "Edificio Anchieta", e homenageando, assim, o grande Apostolo, prepararemos uma elite, capaz de toda a dedicação de que carece o nosso Brasil...arregimentaremos um exercito de gente nova, que não permittirá mais, num futuro muito proximo , a repetição dolorosa do conceito de que o Brasil é um deserto de homens!... Levantemos o Edificio Anchieta (MARTINS, 1934, p. 100).
\end{abstract}

Sob essa ótica, podemos aferir que o Edifício Anchieta não era apenas um monumento arquitetônico, "na solidez inerte da pedra e do aço, na arrogância babélica dos arranhas céus” (MARTINS, 1934, p. 74). Na verdade, entre as aspirações coletivas que permeavam o grupo, uma delas era de que através dessa homenagem edificada, os católicos seriam capazes de enfrentar o laicismo, mas também combater a atividade educacional protestante. A matéria veiculada no jornal $A$ Cruг, sob o título, “Glorificação de Anchieta”, é explícita neste sentido:

Propõe-se a Ação Social Brasileira construir na esplanada do Castelo, em cujos cimos ora arrazoados se alevantava outrora o famoso colegio dos jesuítas, o Edificio Anchieta, a contraporse peito a peito, braço a braço, a insidiosa propaganda protestante da Associação Cristã de Moços! (A CRUZ, 1934, p. 3).

Feitas essas considerações inicias, é importante dizer que o plano ASB-Edifício Anchieta estava dividido em quatro seções: escolar, social, artística e popular. Essas cumpririam a função de "atender a todo o vasto e complexo problema social" por meio de um rol "profilático" de medidas que variavam conforme os objetivos e o público alvo de cada repartição. A seção escolar, por exemplo, constituía-se em um prolongamento auxiliar da escola com medidas que favorecessem a educação física e moral do povo. Os principais destaques dessa seção, segundo a perspectiva de Martins, eram: o cinema educativo e os gabinetes de história, geografia, física e química. Nesse programa há uma nítida bipartição entre "o ensino do povo e o ensino da elite". 
Segundo Martins (s/d), os gabinetes de estudo estariam destinados prioritariamente aos "intelectuais de alta cultura", à disposição todos os dias para os colégios particulares e somente determinados dias à disposição dos estabelecimentos de instrução pública. Para Martins o "povo simples" não precisava de uma instalação científica e intelectual de estudos, mas apenas "salas contiguas de formação physica e moral", visto que, "da cultura popular dependia o aparelhamento da Pátria para o seu destino futuro" (MARTINS, s/d, 62-63).

Posição semelhante encontrava-se também na proposta da seção de artes do plano da ASB. Essa visava, principalmente, a formação de uma intelectualidade artística por meio de um complexo aparato material e técnico, que incluía desde cursos de música sacra, corais e lições, até grandiosos salões acústicos para música de câmera e exposições. Já para o “povo simples, que não pode frequentar o Municipal”, a ASB organizaria o plano de concertos populares, educativos com músicas, principalmente de igrejas (MARTINS, s/d, p. 68).

As seções social e popular definiam-se como aquelas que se ocupariam dos "problemas propriamente do povo", que cooperariam para com os empreendimentos sociais já existentes no país. Contudo a seção social também contemplava uma instalação para organizações científicas e culturais. Segundo nos conta Martins, esse setor seria responsável pelo desenvolvimento de um intercâmbio de estudos entre todas as organizações sociais, no sentido de contribuir para efetivação e defesa de uma "Sciencia social” (MARTINS, s/d, p. 47).

Em outras palavras, Martins (s/d) defendia a aplicação da síntese tomistaleonina como parte integrante de uma ciência social. Uma maneira de empregar diligentemente as orientações e/ou desejos de Pio XI, no sentido de desenvolver a ciência social e econômica, conforme as exigências do tempo, levados, sobretudo, do desejo de tornar a doutrina inalterada e inalterável da Igreja mais eficaz para remediar as necessidades modernas (PIO XI, 1972).

Em suma, esse foi o projeto de assistência social e educacional apresentado por Martins. Não se tratou aqui de uma exposição linear do "Estatuto da Associação", visto que este não foi possível localizar. Trata-se de vestígios de artigos, palestras e conferências que foram publicadas na imprensa periódica e radiofônica, muitos deles, transcritos nas próprias obras de Martins. Esses, ao serem cruzados e interpretados 
em conjunto, contribuíram para fomentar um "esboço" do que veio a ser o plano Ação Social Brasileira.

\section{Considerações finais}

O estudo da trajetória de Amélia de Rezende Martins apresentado pelo presente artigo objetivou resultado capaz de fornecer um enquadramento de sua atuação política e intelectual. Trouxe à cena uma intelectual preocupada com a construção de um projeto de organização social e cultural para o Brasil. Com toda probabilidade as experiências práticas a que Amélia foi exposta indiciam as marcas do seu itinerário de formação, das redes sociais às quais pertenceu e das experiências por ela compartilhadas dentro das duas cidades (Campinas e Rio de Janeiro).

Ademais, demonstrou-nos que as mulheres não foram passivas nesse período. Mas que na verdade elas possuíram uma forma de atuação que lhes é particular, que foi moldada de acordo com suas vivências e possibilidades históricas. Eis a síntese de sua ação militante: o catolicismo social sob perspectiva pastoral.

Por fim, acreditamos que a relevância de visibilizar sua trajetória de militante católica, de produtora cultural e de mulher contribuiu para pensarmos mais do que a relação dessas três categorias - "catolicismo, mulher e política" - no período histórico demarcado. Possibilitou-nos refletir os desdobramentos históricos e a importância das suas ações como reveladoras de uma vasta rede de sociabilidade e das aspirações de muitas vozes silenciadas que contribuíram, junto aos "grandes líderes", para a legitimação das estratégias utilizadas pela Igreja para se fazer presente na sociedade durante a Primeira República. 


\section{Referências}

BAZELAIRE, Louis-Marie de. Os leigos também são a Igreja. São Paulo: Flamboyant, 1960.

BERGER, P.; LUCKMANN, T. A construção social da realidade: tratado de sociologia do conhecimento. Petrópolis: Vozes, 1996.

BORGES, V. P. Georges Leuzinger, seus negócios e sua família: entre o Velho e os Novos mundos. In: Seminário Brasileiro sobre livro e história editorial, 1. 2004, Rio de Janeiro. Anais [...]. Rio de Janeiro: Fundação Casa de Rui Barbosa - FCRB, 2004.

CARVALHO, J. M. de. Brasil 1870-1914: a força da tradição. In: CARVALHO, J. M. de. Pontos e bordados: escritos de história e política. Belo Horizonte: UFMG, 1998.

CARVALHO, M. M. C. de. Molde Nacional e Fôrma cívica: higiene, moral e trabalho no Projeto da Associação Brasileira de Educação (1924-1931). Bragança Paulista: Edusf, 1998.

COUTROT, Aline. Religião e Política. In: RÉMOND, René. Por uma história politica. Rio de Janeiro: UFRJ: FGV, 2003.

DE SANCTIS, A. (frei). Encíclicas e Documentos Sociais. São Paulo: LTR, 1972.

FAUSTO, B. História do Brasil. São Paulo: USP, 2013.

FEMENICK, T. R. Cooperativismo como prática. Tribuna do Norte, 2010. Disponível em: http://www.tomislav.com.br/cooperativismo-como-pratica/. Acesso em: 05 jan. 2019.

GOMES, A. M. de C. Essa gente do Rio: modernismo e nacionalismo. Rio de Janeiro: FGV, 1999.

LAPA, J. R. do A. A cidade: os cantos e os antros. São Paulo: Edusp, 1996.

LEÃO XIII (Papa). Rerum Novarum; carta encíclica de sua santidade o Papa Leão XIII sobre a condição dos operários. 15 maio 1891. In: DE SANCTIS, Antônio. Encíclicas e Documentos Sociais. São Paulo: LTR, 1972. p.13-47.

MALATIAN, T. Narrador, registro e arquivo. In: PINSK, Carla Bassanezi. O bistoriador e suas fontes. São Paulo: Contexto, 2009. p.195-221.

MARTINS, José Pedro Soares. Basilica do Carmo: História de fé no coração de Campinas. Campinas, Ed.Komedi, 2010.

OLIVEIRA, Alexandre Luís de. Dom Sebastião Leme e as estratégias de atuação do catolicismo nos anos 1930. Revista Faces de Clio, UFJF, Minas Gerais, n. 4, p. 88-98, jul./dez. 2016.

PERECIN, M. T. G. Ospassos do saber: a Escola Agrícola Prática Luiz de Queiroz - o esforço para implantar o ensino técnico de segundo grau na agricultura, 1891-1911. São Paulo: Edusp, 2004.

PEREIRA, Armand. Cooperativas: mudanças, oportunidades e desafios. Brasília: OIT, 2001. 
PIO XI. Quadragesimo Anno; carta encíclica de sua santidade o Papa Pio XI sobre a restauração e aperfeiçoamento da ordem social em conformidade com a lei evangélica. 15 maio 1931. In: DE SANCTIS, A. (frei). Encíclicas e Documentos Sociais. São Paulo: LTR, 1972. p. 50-102.

RIGOLO FILHO, P. A romanização como cultura religiosa: as práticas sociais e religiosas de D. João Batista Corrêa Nery, bispo de Campinas, 1908-1920. Dissertação (Mestrado em História) - Universidade Estadual de Campinas, Unicamp, Campinas, 2006.

SIRINELLI, J-F. Os intelectuais. In: Rémond, René. Por uma bistória política. Rio de Janeiro: UFRJ: FGV, 2003.

THOMPSON, E. A miséria da teoria on um planetário de erros: uma crítica ao pensamento de Althusser. Rio de Janeiro: Zahar, 1981.

VALE, S.; et al. Arquidiocese de Campinas: subsídios para sua história. Campinas: Komedi, 2004.

\section{Fontes}

ARQUIVO da Fundação Casa de Rui Barbosa. Dossiê: Amélia Rezende Martins. Rio de Janeiro, n. de chamada RB-RBCRUPF RB-RBCRUPF 896/1, anos 1912, 1919 e 1920.

D’AZEVEDO. A União, Rio de Janeiro, 8 abr. 1920, p. 1.

A CRUZ. Glorificação de Anchieta. A Cru₹, Rio de Janeiro, 24 de jun. 1934, p. 3.

MARTINS, A.R. Uma nova fundação educacional e de assistência social. A Noite, Rio de Janeiro, 19 abr.1933, p.2.

MARTINS, Amélia R. Edifício Anchieta - Acção Social Brasileira. Rio de Janeiro, 1933.

MARTINS, Amélia R. Quinzena Anchietana - A Acção Social Brasileira pela voz do Brasil a Anchieta (1534-1934). Rio de Janeiro: Officinas graphicas Almanak Laemmert, 1934.

MARTINS, Amélia R. Um idealista realizador: Barão Geraldo de Rezende. Rio de Janeiro: Oficina Gráficas do Almanak Laemmert,1939.

MARTINS, Amélia R. Edifício Anchieta. Acção Social Brasileira. Conferência Nacional de Educação, 4. Rio de Janeiro, s.d.

SERRANO, J. Edifício Anchieta. A União, Rio de Janeiro, 26 fev. 1933, s.p.

RECEBIDO: $19 / 03 / 2019$

APROVADO: $15 / 10 / 2019$
RECEIVED: 03/19/2019

APPROVED: $10 / 15 / 2019$
RECIBIDO: $19 / 03 / 2019$

APROBADO: $15 / 10 / 2019$ 